
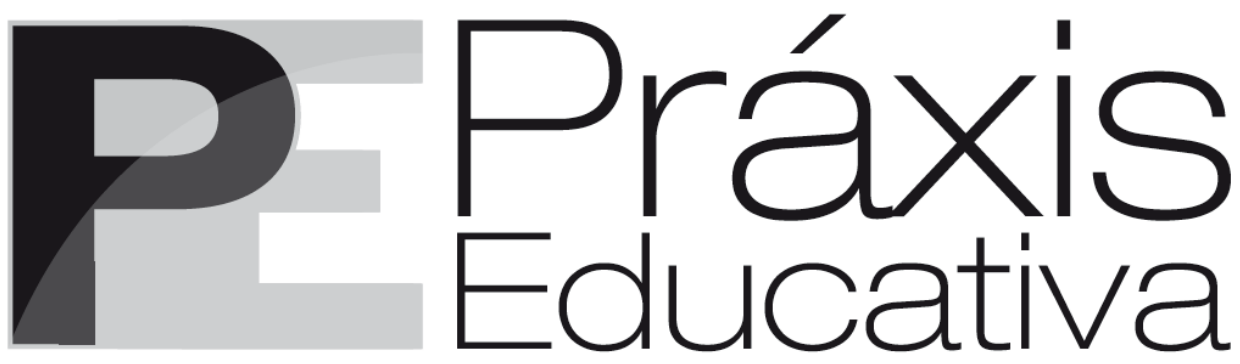

ISSN 1809-4309 (Versão online)

DOI: 10.5212/PraxEduc.v.12i3.012

\title{
Avaliação da Educação Superior no Brasil: discursos, práticas e disputas*
}

\section{Evaluation of Higher Education in Brazil: discourses, practices and disputes}

\section{Evaluación de la Educación Superior en Brasil: discursos, prácticas y disputas}

\author{
Alfredo Macedo Gomes ${ }^{* *}$ \\ Assis Leão da Silva ${ }^{* * *}$ \\ Ana Lúcia Borba de Arruda ${ }^{* * * *}$
}

Resumo: Este texto analisa o campo da Educação Superior, tomando como sujeito-objeto de investigação as políticas de avaliação, o posicionamento e o engajamento de determinados sujeitos na formulação e na implementação das políticas de avaliação da Educação Superior, o que implica explorar facetas relevantes da disputa e da estruturação do campo da Educação Superior no Brasil. A análise explorou documentos e publicações, assim como movimentações e posicionamentos dos sujeitos no campo e na esfera estatal. Argumenta-se que as políticas de avaliação da Educação Superior têm sido permeadas por disputas expressas por meio do posicionamento de grupos que se situam no campo e no aparelho de Estado - MEC, CONAES, INEP - que disputam o campo desde 1990. Dois posicionamentos predominam no campo, o discurso e o modelo de avaliação contextual-participativo e o racional-objetivista. O cenário delineado nos últimos anos permite observar que a introdução de índices por parte das agências estatais promoveu uma virada na condução da política de avaliação, realinhando-a à perspectiva racional-objetivista.

Palavras-chave: Educação Superior. Políticas de avaliação. Brasil.

Abstract: This text analyzes the field of Higher Education, taking as the subject-object of investigation the evaluation policies, the positioning and the engagement of certain subjects in the formulation and implementation of the evaluation policies of Higher Education, which implies exploring relevant dimensions of the dispute and the structuring of the field of Higher Education in Brazil. The analysis explored documents and publications, as well as movements and positioning of the subjects in the field and in the state sphere. It is argued that the evaluation policies of Higher Education have been permeated

\footnotetext{
${ }^{*}$ Apoio financeiro CNPq.

** Professor Associado do Departamento de Fundamentos Sócio-Filosóficos da Educação e professor permanente do Programa de Pós-Graduação em Educação do Centro de Educação da Universidade Federal de Pernambuco. Bolsista em Produtividade CNPq. E-mail: <alfredomgomes@gmail.com>.

*** Professor do Instituto Federal de Educação, Ciência e Tecnologia de Pernambuco/IFPE. Doutor em Educação pela Universidade Federal de Pernambuco. E-mail: <assisleao33@gmail.com>.

**** Professora Adjunta do Departamento de Administração Escolar e Planejamento do Centro de Educação da Universidade Federal de Pernambuco. E-mail: <anaborba@hotmail.com>.
} 
by disputes expressed through the positioning of groups that are situated in the field and in the State apparatus - MEC, CONAES, INEP - that have been disputing the field since 1990. Two positions predominate in the field, the discourse and the model of contextual-participatory evaluation and the rational-objectivist. The scenario outlined in recent years allows to observe that the introduction of indexes by state agencies has promoted a turning point in the evaluation policy conduct, realigning it to a rational-objectivist perspective.

Keywords: Higher Education. Evaluation policies. Brazil.

Resumen: En este texto se analiza el campo de la Educación Superior, tomando como sujeto-objeto de investigación a las políticas de evaluación, el posicionamiento y el compromiso de determinados sujetos en la formulación y en la implementación de las políticas de evaluación de la Educación Superior, lo que implica explorar facetas relevantes de la disputa y de la estructuración del campo de la Educación Superior en Brasil. El análisis exploró documentos y publicaciones, así como movimientos y posicionamientos de los sujetos en el campo y en la esfera estatal. Se argumenta que las políticas de evaluación de la Educación Superior han sido permeadas por disputas expresas por medio del posicionamiento de grupos que se sitúan en el campo y en el aparato de Estado - MEC, CONAES, INEP - que disputan el campo desde 1990. Dos posicionamientos predominan en el campo, el discurso y el modelo de evaluación contextualparticipativa y el racional-objetivista. El escenario delineado en los últimos años permite observar que la introducción de índices por parte de las agencias estatales promovió una viradana conducción de la política de evaluación, realizándola a la perspectiva racional-objetivista.

Palabras clave: Educación Superior. Políticas de evaluación. Brasil.

\section{Introdução}

Se a vida científica fosse saudável, não se poderia tão facilmente reduzir a crítica ao estatuto de "golpe" (baixo) estratégico. Embora constitua o ideal proclamado de nossos ofícios científicos, a discussão crítica, afinal, tem pouco espaço nas práticas efetivas (LAHIRE, 2002, p. 40-41).

Não se pode naturalizar, sob nenhuma hipótese, uma das categorias mais caras à análise crítico-relacional das políticas públicas: o fato concreto, real e inelutável de a política pública constituir, ao tempo que é constituída, por forças atuantes na sociedade e, por isso, estabelecer-se em campo de disputa. $\mathrm{O}$ (ab)uso do termo campo de disputa, sem a devida vigilância epistemológica (BOURDIEU; CLAMBOREDON; PASSERON, 1999), tem levado a uma fragilidade inegável, quando não em ausência tácita, da problematização requerida para a análise das políticas públicas por meio do estudo das forças, grupos e/ou classes sociais implicadas, abrangendo as dimensões estruturais e conjunturais, assim como as respectivas formações discursivas, que dão sentido à análise crítico-relacional das políticas públicas de educação. Para explorar essa ideia-força, não podemos ficar in the abstract, é necessário analisar o que de concreto-discursivo ocorre nas políticas públicas.

Para tanto, analisamos o campo da Educação Superior, tomando como sujeito-objeto (GOMES; OLIVEIRA, 2012) o posicionamento e o engajamento de determinados sujeitos na concepção, na formulação e na implementação das políticas de avaliação da Educação Superior, o que implica explorar facetas relevantes da disputa e da estruturação desse campo no Brasil. A contribuição que o presente texto busca oferecer ao debate das políticas de avaliação da Educação Superior remete, portanto, por um lado, à análise das disputas nesse campo e, por outro, a movimentos, posições e discursos das forças e dos grupos que disputam o campo desde o início dos anos de 1990. A análise explora documentos e publicações do campo da Educação Superior, no primeiro caso leis, decretos, projetos, resoluções, etc., publicados a partir dos anos de 1980 e que enunciam as políticas estudadas e, no segundo caso, publicações dos agentes que 
atuaram (e alguns ainda atuam) ativamente no campo e/ou no aparelho de Estado pelo mesmo período.

De Bourdieu tomamos de empréstimo o conceito de $\operatorname{campo}^{1}$ como um dos referenciais de análise. A partir de Lahire (2002, p. 47), sintetizamos os "[...] elementos fundamentais e relativamente invariantes da definição do campo" de Bourdieu. Afirma Lahire (2002, p. 47) que "[...] um campo é um microcosmo incluído no macrocosmo constituído pelo espaço social (nacional) global". Assim, o campo da Educação Superior está, inapelavelmente, constituído pelo espaço social nacional, em suas dimensões política, econômica, cultural, social e acadêmicocientífica, no qual rivalizam projetos político-ideológicos que se exprimem, não apenas, mas também, nas e por meio das políticas públicas de Educação Superior.

Além disso, "[...] cada campo possui regras do jogo e desafios específicos, irredutíveis às regras do jogo ou aos desafios dos outros campos [...]" (LAHIRE, 2002, p. 47), o que nos leva a pensar que, embora campo subordinado (GOMES; ROBERTSON; DALE, 2012), o campo da Educação Superior possui regras e desafios que nenhum outro campo pode reproduzir nem se apropriar, legitimado pelos fins e pelo modus operandi que lhes é singular.

Contudo, um campo é também um espaço estruturado de posições. Essa dimensão fazse relevante para o reconhecimento de que os sujeitos e/ou grupos sociais não se posicionam livremente no campo, mas em função de linhagens históricas, de certos determinantes, entre os quais se encontram a avaliação das forças e das chances políticas daqueles contra os quais lutam. Não é à toa, pois, que os sujeitos e/ou grupos em disputa se reconhecem e calculam o posicionamento dos demais participantes do campo. No campo da Educação Superior (assim como em outros campos sociais), cuja manutenção e reprodução são fortemente dependentes das políticas públicas, portanto alimentado por complexas e imprevisíveis relações entre sujeitos, grupos, Estado e sociedade civil, os posicionamentos são muitas vezes determinados pelo capital político, pela relação de interesse (inclusive econômica) e pela aproximação com os grupos que estão no poder.

Uma invariante estruturante da noção de campo é que "[...] as lutas se dão em torno da apropriação de um capital específico do campo (o monopólio do capital específico legítimo) e/ou da redefinição daquele capital” (LAHIRE, 2002, p. 47). Nesse caso, pode-se ler que as políticas de avaliação da Educação Superior foram e são fundamentais para (re)definir e regular a distribuição do capital específico legítimo da Educação Superior, o que significa procurar determinar como e por meio de que instrumentos se fazem a avaliação dos elementos centrais e secundários do capital específico da Educação Superior, entre os quais a classificação, a valorização e a legitimação dos títulos, graus e produtos produzidos pelas instituições de Educação Superior.

[...] a distribuição desigual do capital determina a estrutura do campo, que é, portanto, definida pelo estado de uma relação de força histórica entre as forças (agentes, instituições) em presença no campo. As estratégias dos agentes entendem-se se as relacionarmos com suas posições no campo. Entre as estratégias invariantes, pode-se ressaltar a oposição entre as estratégias de conservação e as estratégias de subversão... [...]. Em luta uns contra os outros, os agentes de um campo têm pelo menos interesse em que o campo exista e, portanto, mantêm uma 'cumplicidade objetiva' para além das lutas que os opõem. (LAHIRE, 2002, p. 48, grifos nossos).

\footnotetext{
${ }^{1} \mathrm{O}$ conceito de campo da Educação Superior vem sendo tematizado aqui entre nós por mais de duas décadas (DIAS SOBRINHO, 1999; CUNHA, 2000, 2004; MARTINS, 2000, 1998; HEY, 2008, 2007). Dias Sobrinho (1999, p. 29) afirma que "[...] há fortes razões para acreditar que um novo campo de debates, pesquisas e práticas está se constituindo, principalmente no âmbito da educação superior, portador de possibilidades novas e de grande potencial de disputas".
}

Práxis Educativa, Ponta Grossa, v. 12, n. 3, p. 909-928, set./dez. 2017 Disponível em: <http://www.revistas2.uepg.br/index.php/praxiseducativa > 
No caso aqui explorado, defendemos que a avaliaşão vem sendo disputada, de modo mais sistemático e com crescente visibilidade, desde o início da década de 1990, o que implica a disputa pelo controle da definição da política pública de avaliação e regulação da Educação Superior, o que não é pouca coisa, não porque o Sistema Nacional de Avaliação da Educação Superior (doravante SINAES) tem como objetivo "[...] assegurar processo nacional de avaliação das instituições de educação superior, dos cursos de graduação e do desempenho acadêmico de seus estudantes" (BRASIL, 2004, p. 3), mas pelas forças, pelos grupos de interesses, pelos recursos e pelas posições que mobilizam.

\section{Disputas, políticas de avaliação e modelos de Educação Superior}

O SINAES representa uma tentativa política ambiciosa para estabelecer um modelo compreensivo de avaliação da Educação Superior no Brasil, resultado da ação das forças e dos grupos que, por interesses e projetos em disputas, foram levados a conjugarem as iniciativas de avaliação previamente dominantes no campo, representadas, por um lado, pelo Programa de Avaliação Institucional das Universidades Brasileiras (doravante PAIUB) e, por outro, pelo Exame Nacional de Cursos (doravante ENC) (GOMES, 2002, 2003; BARREYRO; ROTHEN, 2006; BARREYRO; ROTHEN, 2008; ZANDAVALLI, 2009; ZAINKO, 2008; WEBER, 2010; GOMES; SILVA, 2012; SILVA, 2015).

No caso do PAIUB, dominou, por um curto período de tempo, em termos de política de avaliação, o modelo de avaliação institucional interna, repositório de uma formação discursiva que advogava a avaliação formativa e transformadora, evidenciada nos princípios que o orientava e, sobretudo, por se tratar de uma avaliação baseada em contexto e cujos sujeitos centrais da avaliação eram os membros da comunidade universitária (professores, técnicos e estudantes), da qual se queria "[...] intensa participação [...] tanto nos procedimentos e implementação, como na utilização dos resultados, traduzidos em medidas ao aperfeiçoamento da instituição" (BRASIL, 1994, p. 13).

No contexto que compreende o período entre 1993 e 1995, o PAUIB nasce, torna-se $a$ política de avaliação institucional das universidades brasileiras (BRASIL, 1993a), alcança seu apogeu e, em seguida, definha e morre pelas mãos do grupo que assume o MEC em 1995 (GOMES, 2003). É necessário dizer que o "fim" oficial do PAIUB como política de avaliação não estancou a formação discursiva e os valores acadêmicos que o semeia e o projeta para o tempo futuro, porque, como energia que alimenta o campo em disputa, o PAUIB simboliza resistência e possibilidades de transformação do projeto de universidade e da política de avaliação que se colocou no seu lugar, o ENC. Assim, o PAUIB tornou-se bandeira, parâmetro crítico, repositório e arsenal discursivo ao longo da vigência do ENC e, por isso, renasce ressignificado no SINAES.

As forças que dominaram o campo da avaliação da Educação Superior e que propuseram o PAIUB eram, na sua maioria, vinculadas às universidades públicas, federais e estaduais. Entre os nomes desse movimento, que integraram a Comissão de Avaliação da Associação Nacional dos Dirigentes das Instituições Federais de Ensino Superior (ANDIFES) e, depois, a Comissão Nacional de Avaliação (CNA) e/ou o Comitê Assessor da Comissão da Secretaria de Educação Superior do MEC no início dos anos 1990, destacaram-se Hélgio Trindade, Dilvo Ristoff, José Dias Sobrinho, Isaura Belloni, dentre outros.

Além do debate sobre a avaliação da Educação Superior que vinha ocorrendo no período anterior aos anos de 1990, passando pela famigerada lista dos "improdutivos da USP" na década de 1980, tivemos na primeira metade dos anos 1990 a ascensão de Itamar Franco à Presidência da

Práxis Educativa, Ponta Grossa, v. 12, n. 3, p. 909-928, set./dez. 2017 Disponível em: <http://www.revistas2.uepg.br/index.php/praxiseducativa > 
República, que nomeia Murilo Hingel como Ministro da Educação em 1992. Tratava-se, é evidente, de um governo de transição que, entre outros aspectos, foi marcado pelo discurso de fortalecimento da universidade pública, em face da importância de construir um governo com apoio amplo da população e, especialmente, da comunidade acadêmica. Conforme salienta Trindade, no governo Collor,

[...] a avaliação era vista como algo que se impunha de cima para baixo, associando-se a ela a ideia de punição que se traduzia por sanções, inclusive, no próprio financiamento da universidade. Com o Ministro Murilo Hingel, ao contrário, o clima se distensionou nas relações entre o governo e as universidades, e os dirigentes destas tiveram a sensibilidade política de aproveitar essa brecha, em parceria com o MEC [...]. (TRINDADE, 1996, p. 10).

Por outro lado, a ação dos sujeitos citados, no espaço institucional e na esfera política nacional, deve ser destacada em função do posicionamento estruturante para o campo da Educação Superior e, especialmente, para o campo da avalição desse nível de ensino. Não se quer, obviamente, apresentar aqui qualquer julgamento sobre a biografia de importantes e destacados sujeitos, mas procurar estabelecer as relações que possam ajudar a esclarecer a contextura espaço-temporal das disputas que formam o campo da Educação Superior, especialmente do germe frutífero do regime avaliativo-regulatório e de sua posição estratégica para a gestão institucional e para a gestão da Educação Superior.

Hélgio Trindade foi reitor da Universidade Federal do Rio Grande do Sul (UFRGS) entre 1992 e 1996, o que o possibilitou a compor a Comissão Nacional de Avaliação da SESu/MEC, representando a ANDIFES. A partir de 1994, ele passou a publicar textos tratando da avaliação da Educação Superior, nos quais apresenta a defesa incondicional do projeto de universidade que o PAIUB representava (TRINDADE, 1994, 1995, 1996).

Em torno do mesmo período, Dilvo Ristoff foi Pró-Reitor de Graduação da Universidade Federal de Santa Catarina (UFSC), presidiu o Fórum Nacional dos pró-reitores de Graduação da ANDIFES e integrou o Comitê Assessor da Comissão Nacional de Avaliação. A partir de 1994, ele começou a escrever sobre avaliação da Educação Superior, vinculado ao projeto de universidade que o PAUIB abraça (RISTOFF, 1994, 1995, 1996a, 1996b, 1997a, 1997b).

Entre 1990 e 1994, José Dias Sobrinho foi Pró-Reitor de Pós-Graduação da Universidade de Campinas (UNICAMP), presidiu a Comissão de Avaliação do Desenvolvimento Institucional da UNICAMP, entre 1991 e 1994, e integrou o Comitê Assessor da Comissão Nacional de Avaliação. Além de coordenar a experiência de avaliação institucional da UNICAMP, passou a publicar, a partir de 1994, sobre a temática da Educação Superior associada ao projeto de universidade do qual o PAIUB é parte (DIAS SOBRINHO, 1994a, 1994b, 1995a, 1995b, 1996, 1997; DIAS SOBRINHO; BALZAN, 1995)² e foi fundador da Revista Avaliação, cujo primeiro número foi publicado em 1996.

Considerando o exposto, podemos inferir que:

1) A experiência na gestão universitária - reitor, pró-reitor, etc. -, que se traduz como posicionamento político no campo da Educação Superior em defesa de um projeto de universidade pública, vivenciada como problemas e desafios da universidade brasileira, levam os sujeitos à compreensão prática de que a avaliação é uma ferramenta imprescindível ao

\footnotetext{
${ }^{2}$ Não há registro de publicações anteriores a 1994. As publicações tratam da questão da avaliação institucional e da Educação Superior.
} 
processo de gestão, planejamento e transformação da universidade pública elitista em instituição democrática (DIAS SOBRINHO, 2004; TRINDADE, 1994).

2) O envolvimento político na gestão universitária também cria as condições para o posicionamento efetivo no cenário nacional, inicialmente nos fóruns nacionais da ANDIFES, que se tornaram centrais ao debate da policy issue de avaliação da Educação Superior, pelo acúmulo de experiências (DIAS SOBRINHO; BALZAN, 1995) e pelo momentum político criado com o governo Itamar Franco, que se avoluma no sentido da proposição de uma política de avaliação institucional da Educação Superior pela ANDIFES. A experiência de avaliação institucional da UNICAMP (DIAS SOBRINHO, 1994a, 1994b, 1995a, 1995b) tornou-se um parâmetro, assim como as negociações realizadas entre a ANDIFES e o MEC (TRINDADE, 1996). A Comissão Nacional de Avaliação da SESu/MEC (BRASIL, 1993b), parte do projeto avaliativo em curso, surgiu como proposição dos sujeitos políticos reunidos na e pela ANDIFES.

3) A experiência na gestão e o posicionamento/envolvimento político no projeto nacional em torno da universidade pública provocaram uma ruptura na carreira acadêmica dos sujeitos em questão, sobretudo em termos dos temas pesquisados. Tal ruptura ocorreu por volta de 1995, ano em que o PAIUB foi atacado dentro do MEC e foi substituído pelo modelo de avaliação externa, que se materializou no ENC (BRASIL, 1996).

Por outro lado, durante o mesmo período, além dos sujeitos anteriormente agrupados, posicionava-se no campo da Educação Superior um outro grupo de sujeitos vinculado ao Núcleo de Pesquisas sobre Ensino Superior (NUPES) da Universidade de São Paulo (USP). Entre os seus principais representantes estavam, à época, Eunice Ribeiro Durham, Maria Helena Magalhães Castro e Simon Schwartzman (DURHAM, 1996a, 1996b; PALHARINI, 1998; BARREYRO; ROTHEN, 2010; HEY, 2007, 2008). Com inserção acadêmica e na formulação das políticas governamentais, participaram ativamente da disputa do campo da Educação Superior nos anos de 1990, participação que se projeta ao tempo presente. Pode-se observar a atuação do NUPES, por meio de seus integrantes, em dois governos na esfera Federal, o de Fernando Collor de Mello (1990-1992) e o de Fernando Henrique Cardoso (1995-2001) - último cenário de profunda reforma do Estado e da Educação Superior no País. Palharini (1998) afirma que:

Ao final de 1989, Fernando Collor de Mello é eleito Presidente da República do Brasil e convida a ocupar a pasta do Ministério da Educação José Goldemberg, Reitor da USP que havia, por meio de portaria do ano anterior, dado existência ao NUPES. Acompanha-o nessa empreitada, Eunice Ribeiro Durham, que vem a ocupar a Secretaria do Ensino Superior e, logo após, cumulativamente, a Fundação CAPES. No Governo Fernando Henrique Cardoso, estando à frente do MEC o Ministro Paulo Renato, Eunice Ribeiro Durham passa a ocupar a Secretaria de Política Educacional, da qual se afastou, nessa mesma gestão, para assumir a condição de membro da Câmara de Ensino Superior do Conselho Nacional de Educação (CNE). Destaca-se também a participação em comissões e assessorias junto ao MEC de Simon Schwartzman ([em 1998], presidente do Instituto Brasileiro de Geografia e Estatística - IBGE), Maria Helena M. Castro [Atuou como gerente de projetos de pesquisa no NUPES/USP (1990-92); realizou diversos estudos para o BID; para o INEP/MEC - onde colaborou no desenvolvimento do SIEd-Sup (1999-2000); assessorou o Conselho de Reitores das Universidades Brasileiras-CRUB no desenvolvimento do Programa de Avaliação Institucional e a Presidência do IBGE em matérias de cooperação técnica internacional]. (PALHARINI, 1998, p. 101).

Práxis Educativa, Ponta Grossa, v. 12, n. 3, p. 909-928, set./dez. 2017 Disponível em: <http://www.revistas2.uepg.br/index.php/praxiseducativa > 
Originalmente, o NUPES foi pensado com o intuito de promover um projeto político para Educação Superior concernente às universidades públicas de São Paulo (GRELLO, 2008; BARREYRO; ROTHEN, 2010). No entanto, veio a ser, devido à ascensão do grupo político ao poder no âmbito federal, um think tank que marcou de maneira capital os rumos do Ensino Superior no Brasil ${ }^{3}$. Esse projeto alcançou o campo da Educação Superior em dois momentos: com o ministro da educação José Goldemberg (1991-1992) e, a partir de 1995, com o ministro Paulo Renato Sousa: o projeto subsidia as reformas da Educação Superior, consagra a crítica ao chamado "modelo único" de universidade, promoveu a diferenciação das Instituições de Educação Superior (IES) (BRASIL, 1995; DURHAM, 1996a, 1996b) e criou as condições para a expansão do Ensino Superior via criação de um "moderno mercado da educação superior" (GOMES, 2002). Enfim, representou a modernização do sistema para torná-lo funcional à mercantilização da Educação Superior e ao modo de produção capitalista.

Foi nesse contexto que o NUPES fez a proposição de política de avaliação e de regulação da Educação Superior que visava dar ao Estado a ambiência de legitimidade as suas ações no campo desse nível de ensino. Esse movimento materializou-se no ENC, que encarnava o projeto de avaliação e de Educação Superior distinto do grupo citado anteriormente, pois, entre outras coisas, associava a avaliação ao contingenciamento de verbas públicas e à eficácia orçamentária das IES públicas. Silva (2015) destaca que:

\begin{abstract}
Nesse contexto de embates e tensões entre perspectivas distintas de educação superior, verifica-se que a política de avaliação, à época, foi construída a partir de alterações do marco legal e institucional, em meados da década de 1990, concomitante ao PAIUB. Entre as principais alterações do marco legal... encontra-se a Lei ${ }^{\circ}$ 9.131/95, que estabeleceu o Exame Nacional de Cursos (ENC); a Lei no 9.394/96, que estabelece as Diretrizes e Base da Educação Nacional (LDB), propondo amplo processo de descentralização, flexibilização e novas formas de controle, sobretudo por meio de avaliações periódicas; e o decreto $n^{\circ} 2.026 / 96$ que estabelecia procedimentos para o processo de avaliação dos cursos e IES, fornecendo subsídios para a Análise das Condições de Oferta dos Cursos de Graduação (ACOC) (SILVA, 2015, p. 176).
\end{abstract}

A disputa do campo por projetos distintos de Educação Superior articula-se também com a agenda governamental, não apenas à época, mas também durante os governos FHC, Lula/Dilma e Temer, que vêm promovendo mudanças no campo da avaliação da Educação Superior com implicações significativas sobre a concepção das políticas de avaliação, relevando os interesses dos sujeitos por determinados modelos, práticas e instrumentos de avaliação nesse campo.

A atuação dos sujeitos, formuladores de políticas públicas de Educação Superior, posicionando-se em defesa de projetos distintos para e no campo da Educação Superior brasileira, materializa-se pela participação sistemática nos fóruns e nas agências governamentais, nos debates realizados nos espaços político-acadêmicos, assim como na literatura acadêmica nacional, com impacto considerável na estruturação do campo da Educação Superior brasileira.

\footnotetext{
${ }^{3}$ O NUPES promoveu dois seminários em 1989 e 1990. O primeiro, sob o título de Situação e perspectivas do Ensino Superior no Brasil, teve por objetivo refletir sobre as políticas e fazer um amplo diagnóstico dos principais problemas da Educação Superior no Brasil (DURHAM; SCHWARTZMAN, 1990). O segundo seminário recebeu o título de Avaliação da Educação Superior. As publicações pelo NUPES dos textos do seminário revelaram a relevância estratégica do debate sobre as políticas de avaliação da Educação Superior e o posicionamento que viria a disputar e dominar o campo futuramente (MARTINS, 1990; SCHWARTZMAN, 1990; GOLDEMBERG, 1990; NEIVA, 1990; PAUL; RIBEIRO; PILLATI, 1990; MATTOS, 1990; DURHAM, 1990).
}

Práxis Educativa, Ponta Grossa, v. 12, n. 3, p. 909-928, set./dez. 2017 Disponível em: <http://www.revistas2.uepg.br/index.php/praxiseducativa $>$ 


\section{O campo da Educação Superior e a avaliação nos anos 2000}

A ascensão ao MEC do grupo liderado por Paulo Renato Souza (1995-2002) pôs fim ao PAIUB como política oficial de avaliação. Entretanto, a avaliação continua sendo disputada, sobretudo em face de seu caráter estratégico para a gestão e regulação não apenas do sistema em si, mas do próprio campo de Educação Superior. As universidades públicas e a ANDIFES perceberam no new public management uma visão radicalmente contrária aos princípios defendidos no PAIUB.

O campo da Educação Superior passa a lidar então com as políticas formuladas pelos neotecnocratas, então situados no MEC, originários do NUPES ${ }^{4}$, para os quais as reformas da era FHC precisavam ocorrer para reposicionar as instituições de Educação Superior em "novo patamar". Na perspectiva crítica de Chauí (1999, p. 211), no novo patamar, “[...] o mercado é portador de racionalidade sócio-política e agente principal do bem-estar da república". Esse grupo formulou e implementou o ENC, que perdurou por praticamente oito anos (de 1996 a 2003). Com a posse do Presidente Lula em 2003, um novo cenário político configura-se, anunciando expectativas quanto à viabilização de outro paradigma de avaliação, materializado no SINAES.

As forças que formularam o PAUIB se reagruparam em torno do projeto vitorioso liderado por Lula em 2002, muitos dos quais se tornaram membros da Comissão Especial de Avaliação da Educação Superior ${ }^{5}$ (CEA), que formularam a proposta do SINAES (BRASIL, 2003).

Com a implementação do SINAES, vários obstáculos foram adquirindo visibilidade na política de avaliação, sobretudo entre os anos de 2004 e 2008, entre os quais a desarticulação entre a avaliação interna e externa; a desarticulação entre o Exame Nacional de Desempenho Estudantil (doravante ENADE), a Avaliação das Instituições de Educação Superior (AVALIES) e a Avaliação das Condições dos Cursos de Graduação (ACG); e a fragilidade da avaliação em fundamentar a regulação da Educação Superior da maneira demandada pelo MEC (SILVA; GOMES, 2011; SILVA, 2015).

Por essa razão, alguns integrantes da coordenação e da operacionalização do SINAES foram levados a sair da CONAES e do INEP, o que criou as condições para a introdução das mudanças consideradas necessárias pelo MEC, durante a gestão de Fernando Haddad. Entre outros, compunha a CONAES Hélgio Trindade (que a presidiu entre 2004 e 2006), Dilvo Ristoff (então Diretor de Avaliação do Inep) e José Dias Sobrinho, membro de notório saber. A saída e a substituição deles coincidem com a criação do Índice Geral de Cursos (IGC) e do Conceito

\footnotetext{
${ }^{4}$ Referimo-nos ao grupo situado em São Paulo, dos quais se destacaram Eunice Durham, ex-secretária de Política Educação do MEC; Maria Helena Guimarães Castro, presidente do INEP de 1995 a 2002, atualmente é Secretária Executiva do MEC na gestão Mendonça Filho; e Simon Schwartzman, dentre outros, que contribuíram na reforma e na reformulação das políticas de Educação Superior durante o governo FHC, entre as quais o Exame Nacional de Cursos (ENC).

${ }^{5}$ Esta comissão instituída pelas Portarias MEC/SESu no 11 e no 19 (BRASIL, 2003) foi composta por membros da Secretaria da Educação Superior (SESu), do Instituto Nacional de Estudos e Pesquisas Educacionais Anísio Teixeira (INEP) e onze (11) especialistas ligados às universidades públicas e privadas. Presidida pelo professor José Dias Sobrinho (UNICAMP), a Comissão Especial de Avaliação foi integrada pelos seguintes membros: professores Dilvo Ilvo Ristoff (UFSC), Edson Nunes (UCAM), Hélgio Trindade (UFRGS), Isaac Roitman (CAPES), Isaura Belloni (UnB), José Ederaldo Queiroz Telles (UFPR), José Geraldo de Sousa Junior (SESu), José Marcelino de Rezende Pinto (INEP), Júlio César Godoy Bertolin (UPF), Maria Amélia Sabbag Zainko (UFPR), Maria Beatriz Moreira Luce (UFRGS), Maria Isabel da Cunha (UNISINOS), Maria José Jackson Costa (UFPA), Mario Portugal Pederneiras (SESu), Nelson Cardoso Amaral (UFG), Raimundo Luiz Silva Araújo (INEP), Ricardo Martins (UnB), Silke Weber (UFPE) e Stela Maria Meneghel (FURB).
}

Práxis Educativa, Ponta Grossa, v. 12, n. 3, p. 909-928, set./dez. 2017 Disponível em: <http://www.revistas2.uepg.br/index.php/praxiseducativa $>$ 
Preliminar de Cursos (CPC). Nessas condições, é preciso chamar a atenção para o sentido que o termo implementação assume neste trabalho, uma vez que se pretende enfatizar mudanças recentes e relevantes na política de avaliação da Educação Superior (SINAES), promovida pelo MEC, as quais vieram acompanhadas ou articuladas à substituição de importantes membros da CONAES, herdeiros do PAIUB, que se posicionavam fortemente em defesa do projeto de avaliação institucional no SINAES, portanto insubmissos à prática avaliativa cuja regulação estatal remetia aos mecanismos do mercado educacional. A virada política no SINAES provocou uma resposta cujo testamento foi a publicação de vários artigos na Revista Avaliação (ver. v. 13, n. 3, 2008) ${ }^{6}$.

Essas publicações representaram uma crítica ao que classificamos como discurso da avaliação racional-objetivista, caracterizado pela avaliação como instrumento de controle, materializada nos índices e no fortalecimento do ENADE. Segundo House (2000), a perspectiva "objetivista" dos modelos "gerenciais de avaliação" tende a equiparar à objetividade a quantificação. Dessa maneira, "[...] a escola gerencial em regra baseia-se também em uma epistemologia comum, que é denominada de 'objetivista'. Se considera que a informação da avaliação é 'cientificamente objetiva"' (HOUSE, 1994, p. 49).

Por outro lado, tais publicações retomam o que denominamos de discurso da avaliação contextual-participativa, caracterizado como instrumento de proposição, a partir da "perspectiva" naturalista e democrática. Discurso de avaliação, nesse caso, almeja a generalização naturalista experiência dos destinatários em detrimento dos técnicos -, apropriando-se de narrativas e categorias cotidianas de acontecimentos, baseando-se em uma lógica informal. Por isso, entendese que seus relatórios devam ser apresentados como estudo de caso. Propõe-se mais um modelo qualitativo do que quantitativo. O objetivo consiste em melhorar a compreensão dos indivíduos e das instituições. Esse discurso, de base subjetivista, considera a educação e o ensino como ação pedagógica, mais do que como um conjunto de técnicas explícitas e exteriorizadas. Por essa razão, por exemplo, a avaliação nessa condição produz o conhecimento como processo negociado, em que a participação ativa dos diversos sujeitos constitui-se em uma ideia-chave e estruturante (SILVA, 2015).

De todo modo, cabe lembrar que nas políticas de avaliação da Educação Superior, a partir dos anos de 1990, foram operadas mudanças substantivas no seu delineamento, principalmente em relação à concepção e aos pressupostos teórico-metodológicos, suscitando na e entre a comunidade universitária, agentes governamentais e a mídia interessada, intensos debates a respeito da sua importância e da posição estratégia vis-à-vis da regulação da Educação Superior. O debate das mudanças introduzidas em 2008 não fugiu à essa tendência (BARREYRO, 2008; DIAS SOBRINHO, 2010; ZAINKO, 2008; SILVA, 2015).

Tais disputas posicionam a avaliação como ferramenta central das políticas que marcam a história recente da Educação Superior brasileira, desencadeando transformações nos modelos de avaliação e nos processos de regulação, gestão e controle do modus operandi das Instituições de Educação Superior (CATANI; OLIVEIRA; DOURADO, 2004; GOMES; AZEVEDO, 2009).

\footnotetext{
${ }^{6}$ No volume 13, número 3, de 2008, da Revista Avaliação, destacam-se os seguintes artigos: José Dias Sobrinho Qualidade, avaliação: do SINAES a indices; Maria Amelia Sabbag Zainko - Avaliação da educação superior no Brasil: processo de construção histórica; Denise Leite - Ameaças pós-rankings sobrevivencia das CPAS e da auto-avaliação; Márcia Regina F. de Brito - O SINAES e o ENADE: da concep̧ão à implantação; Jaime Giolo - "SINAES" intermitentes; Amir Limana Desfaz̧endo mitos: o que estão fazendo com o SINAES?. No editorial, Dias Sobrinho identifica as forças atuantes no campo da Educação Superior: "Dois paradigmas disputam a hegemonia na avaliação da educação superior. Uma avaliação de orientação produtivista e marcadamente quantitativista, predominante, atualmente, cujos critérios e metodologias quase sempre são determinados externamente, e, por outro lado, um modelo de avaliação democrático e participativo, socialmente construído e que instaura uma relação dialógica entre a comunidade acadêmica e os representantes dos organismos estatais" (DIAS SOBRINHO, 2008a, p. 623).
}

Práxis Educativa, Ponta Grossa, v. 12, n. 3, p. 909-928, set./dez. 2017 Disponível em: <http://www.revistas2.uepg.br/index.php/praxiseducativa> 
Pode-se dizer que tais disputas ${ }^{7}$ configuram a avaliação da Educação Superior como um espaço de poder irredutível às lutas desse campo, visto que é mais que uma simples confrontação teórica ou meramente acadêmica de sujeitos ou grupos em disputa por uma hegemonia semântica, embora seja também isso. Trata-se, usando aqui palavras de Bourdieu (1989, p. 164), de "[...] um lugar em que se geram, na concorrência entre agentes [...] produtos políticos, problemas, programas, análises, comentários, conceitos, acontecimentos, entre os quais os cidadãos comuns, reduzidos ao estatuto de consumidores, devem escolher".

Mesmo sob o risco de simplificar a realidade estudada e a emoldurá-la em quadro dicotômico e empobrecedor, propomos, para efeito de contribuição para a compreensão dos argumentos e dos pressupostos aqui desenvolvidos, que tais disputas materializam-se no embate entre os que defendem os exames ou testes padronizados, coordenados pelas agências governamentais, cujo cimento que o sustenta é o discurso da avaliação racional-objetivista, caracterizado por práticas avaliativas que se orientam pela mensuração de desempenho e de resultados, com o estabelecimento de hierarquias e rankings, ênfase no controle técnicoburocrático e nos instrumentos elaborados externamente, como exames nacionais, avaliação em larga escala, e avaliação institucional externa (SOUZA, 2005; DURHAM, 2003; CASTRO, 2009). $\mathrm{E}$, por outro lado, os que defendem a avaliação coordenada de dentro e realizada pela comunidade universitária, baseada no discurso da avaliação contextual-participativa, caracterizado pela perspectiva formativa, processual, pedagógica, com pretensões emancipatórias, propositivas e transformadoras, com ênfase no respeito à identidade institucional e na participação ampla ou democrática nos processos e nas atividades avaliadas (DIAS SOBRINHO, 2004; PEIXOTO, 2004; SAUL, 2001).

Desse modo, observa-se, no primeiro caso, a preponderância do discurso do controle e da verticalização da qualidade articulada ao desempenho e à eficiência do sistema de Educação Superior, que procura reduzir a concepção de avaliação às dimensões de supervisão e regulação por meio de instrumentos e de mecanismos externos de verificação da eficácia acadêmica e "social" de cursos, de instituições e de docentes. No segundo caso, o exercício de práticas avaliativas constituídas a partir do discurso da horizontalização da qualidade, aparentemente construídas coletivamente, articulada aos processos de regulação e de supervisão internos originados na comunidade e na gestão universitária das Instituições de Educação Superior.

O cenário delineado a partir de 2005 permite observar mais uma vez o embate de poder em torno da avaliação da Educação Superior, ressignificado pela implementação de "índices" no campo da prática discursiva, quais sejam: Conceito Preliminar de Curso (CPC), instituído pela Portaria Normativa No 4, de 5 de agosto de 2008 (BRASIL, 2008a); e o Índice Geral de Cursos (IGC), instituído pela Portaria Normativa No 12, de 5 de setembro de 2008 (BRASIL, 2008b).

\footnotetext{
7 Com todo o risco de simplificação que a síntese implica, pode-se dizer que essas disputas revelam-se, nas três últimas décadas, em três momentos distintos que marcam as políticas de avaliação da Educação Superior no Brasil: de 1990 a 1994, quando foi dominante o Programa de Avaliação Institucional das Universidades Brasileiras (PAIUB); entre 1996 a 2003, galvanizado pelo Exame Nacional de Cursos (ENC/PROVÃO); e o período que se inicia em 2004, marcado pela montagem, pela implementação e pelas transformações do SINAES. Há relevantes trabalhos que documentam e analisam dimensões diferentes dessas disputas: Gomes (2002), Peixoto (2004), Barreyro e Rothen (2006, 2008), Zandavalli (2009), Zainko (2008), Dias Sobrinho (2008b, 2010), Polidori (2009), Gomes e Silva (2012), Palharini (1998).
} 


\section{Avaliação da Educação Superior: o SINAES ressignificado}

A proposta de avaliação SINAES, construída pela CEA (BRASIL, 2003), foi concebida com o intuito de articular, de maneira sistêmica, as modalidades de avaliação institucional de cursos e de desempenho estudantil. No entanto, a implementação do SINAES pouco se aproximou da proposta original.

A articulação entre modelos de avaliação com características distintas estabelecido pela Lei do SINAES (BRASIL, 2004) foi afetada, entre outros motivos, pela implantação acelerada do ENADE, e a ampla visibilidade que lhe foi dada pelo MEC, e pela persistente dificuldade de implementação do processo de avaliação institucional (CPAs) e de curso, minando e despotencializando a fundamentação dos processos regulatórios e de supervisão, por parte do Estado, que deveriam amparar-se em uma perspectiva de avaliação contextual-participativa.

Nesse contexto, a conjectura e o desenvolvimento de índices por parte das agências estatais de coordenação e de operacionalização, respectivamente, CONAES e INEP, promoveram uma virada relevante na condução da política de avaliação da Educação Superior, no sentido da perspectiva racional-objetivista. Tal virada, entre outras razões, só foi possível em razão da substituição e da renovação de membros da CONAES e de quadros do INEP.

Os defensores de mudanças no SINAES advogaram em favor da introdução dos índices sob o argumento de reequilibrar o Sistema Nacional de Avaliação da Educação Superior, para combater os efeitos da acelerada implementação do ENADE e as dificuldades de implementação do AVALIES em suas duas modalidades básicas. A mudança adveio de proposições que visavam e visam superar os obstáculos - entre eles, o tempo do ciclo de avaliação - postos às modalidades de avaliação institucional interna e externa e de cursos no SINAES. O tempo do ciclo de avaliação é considerado fator essencial e delimitador da eficácia e do alcance da avaliação sistêmica. Por essa razão, a questão capital nessas proposições reside no peso atribuído, pelos formuladores do SINAES, à avaliação in loco para fins regulatórios. Dessa maneira, a ressignificação da avaliação in loco por meio dos índices conferiu visibilidade a duas outras questões centrais: quem avalia e como avalia.

Em relação a "quem avalia", foram introduzidas, nos últimos anos, mudanças no Banco de Avaliadores (BASIs) para garantir mais credibilidade e legitimidade às avaliações in loco, por meio da requalificação da formação, da instalação de processos meta-avaliativos das comissões externas de avaliação institucional e exclusão do BASIs de avaliadores envolvidos em experiências de avaliação não exitosas. Foram também estabelecidos critérios mais rigorosos para seleção das comissões, assim como definido um ciclo mais claro para a realização da avaliação externa (BRASIL, 2016).

Com relação à "como se avalia", foram introduzidas medidas que levaram a reformulação dos instrumentos de avaliação com a inserção de novos indicadores e a reformulação da estrutura logística para realização das visitas in loco, claro, como consequência da introdução dos índices em 2008: do CPC, utilizado no processo de renovação de reconhecimento no ciclo avaliativo; e do IGC, relacionado à autonomia das IES para autorizar cursos. Em 2009, o ENADE passa a ser censitário. Em 2010, a criação do Banco Nacional de Itens (BNI) da Educação Superior (BRASIL, 2016). Em 2011, o ENEM passa a ser utilizado como resultado dos ingressantes no ENADE e este passa a ser aplicado apenas aos concluintes. Em 2012, foram homologados o novo instrumento de avaliação de cursos, o início do processo de avaliação dos avaliadores in loco e da autoavaliação e a revisão dos insumos do CPC (INEP, 2014b).

Práxis Educativa, Ponta Grossa, v. 12, n. 3, p. 909-928, set./dez. 2017 Disponível em: <http://www.revistas2.uepg.br/index.php/praxiseducativa > 
Essas medidas foram acompanhadas de críticas ao processo de implementação da política de avaliação da Educação Superior vigente (LEITE, 2008; SILVA; GOMES, 2011), as quais focalizaram a valorização e a ênfase conferidas aos processos de avaliações externas em detrimento dos processos de avaliação interna, assim como, em relação ao ENADE, a introdução e o desenvolvimento dos índices que buscaram proporcionar sentido às reformulações propostas às avaliações externas institucional e de curso, o que implicou no esvaziamento do papel das Comissões Próprias de Avaliação (CPAs) nas IES (VERHINE, 2015).

Reconhecendo parte das limitações na implementação da avaliação institucional no tocante aos agentes internos, a CONAES, a partir de sua recomposição entre 2006 e 2008, vem propondo uma série de medidas pontuais para atenuar os problemas postos à implementação dessas modalidades de avaliação, entre elas: a fixação de uma data para a entrega dos relatórios de avaliação interna; a realização de seminários para tratar dos entraves gerais à materialização da política e, especialmente, dos aspectos da implementação da avaliação institucional; a publicação de experiências das CPAs; a avaliação interna, que passou a ser o foco das avaliações externas não apenas de instituições, mas também das comissões de avaliação de cursos; além de novas orientações para a autoavaliação e proposição do novo roteiro e ciclo avaliativo para o relatório de avaliação interna caracterizado nas notas técnicas no 62 e no 65 de 2014 (MENEGHEL, 2014; INEP, 2014a, 2014b).

Associados a essas ações, o INEP vem desenvolvendo indicadores específicos para fomentar e avaliar a avaliação interna nas IES e o trabalho das CPAs, induzindo a problematização de questões relevantes para estruturação dos trabalhos da avaliação interna, tais como: institucionalização das CPAs, condições de trabalhos para seus membros, apoio técnico, estabelecimento de critérios para indicação dos membros, estímulo à participação da comunidade acadêmica e da sociedade civil, e autonomia no desenvolvimento e divulgação do trabalho avaliativo. No entanto, é preciso indagar sobre as reais intenções dos segmentos representados na CONAES em relação ao desenvolvimento dessas medidas na implementação da avaliação interna.

Essas medidas demonstram a ressignificação da lógica da avaliação para enfatizar a "eficiência", a "eficácia", a "utilidade" e a "competitividade" das IES, substanciada na valorização da prestação de contas e nos processos de acreditação, tornando-a mais burocrática e formal (SILVA, 2015). Nesse caso, os diagnósticos levantados pelas avaliações interna e externa têm servido mais para registro e tomada de decisão da regulação estatal do que aos processos de mudanças nas instituições.

Nesse contexto, a lógica da avaliação centra-se no provimento de informações para a ação ao nível dos agentes estatais e do mercado educacional. Sua principal justificativa é que ela colabora para a racionalização da tomada de decisão. Desse modo, é preciso lembrar a concepção original do SINAES: a avaliação constitui-se em mecanismo-base para as decisões compartilhadas. No contexto analisado, a lógica atribuída à racionalização da tomada de decisão por meio dos diagnósticos da avaliação vem se distanciando de sua concepção original, uma vez que a avaliação tem servido preferencialmente à regulação estatal-mercantil em detrimento da regulação da comunidade/pares e da qualidade da Educação Superior.

Os argumentos apresentados demonstram que o formato gerencial que a avaliação assume desde 2008 altera a sua concepção, pois nesse âmbito a avaliação inibe a ampliação das formas de participação e o envolvimento democrático dos agentes/segmentos da comunidade universitária nas IES e da sociedade civil, bem como restringe a adoção de procedimentos metodológicos que viabilizem o diálogo e a articulação entre as IES, a sociedade e o Estado, 
revelando a cultura do silenciamento, da aparente neutralidade, da burocratização e do formalismo em torno dos processos de avaliação interna e externa.

Nesse contexto, o SINAES, como projeto de avaliação da Educação Superior, passou por profunda mudança e ressignificação no sentido da perspectiva racional-objetivista. Os grupos defensores da avaliação na perspectiva contextual-participativa, materializada na proposta original do PAIUB e do SINAES, foram derrotados. Esse fato atenta para mudanças importantes realizadas no regime avaliativo-regulatório. Em relação à avaliação, ela continua a fundamentar a regulação, porém associada a uma regulação visível e proeminentemente estatal-mercantil em detrimento da regulação baseada na comunidade universitária.

\section{Considerações finais}

Propôs-se, ao longo deste trabalho, analisar a disputa no campo da avaliação da Educação Superior, demonstrando movimentos, posições e discursos das forças e dos grupos que concorrem nesse campo desde o início dos anos de 1990 e suas influências na atual política de avaliação desse nível de ensino. Com a ruptura da prática dos grupos inseridos no campo da avaliação da Educação Superior em prol de uma avaliação na perspectiva contextual-participativa, o SINAES parece ser destituído de sua ideia-força originária - a ideia de comunidade avaliativa. Consequentemente, esvazia-se a expectativa propositiva da avaliação em torno do diálogo pedagógico e autorregulatório. Percebe-se, portanto, a tendência de redução da avaliação à classificação e à simplificação de suas funções e à provisão de informações para as agências estatais e para o mercado educacional.

Considera-se que essas mudanças no SINAES são uns dos motivadores do debate atual sobre a avaliação da Educação Superior. Além de possibilitar visualizar tanto as dificuldades quanto os obstáculos postos à implementação da política de avaliação, elas permitem também compreender a natureza dos interesses e das lutas entre grupos, forças e projetos de avaliação e de Educação Superior, motivadores de reformas tanto na implementação quanto no desenho da política de avaliação no decorrer das últimas três décadas.

É necessário afirmar que as mudanças ocorridas na Educação Superior, em particular nas políticas de avaliação, não aconteceram de uma única vez; foram resultados de ações de grupos posicionados estrategicamente nesse campo que ocuparam posições importantes no aparelho estatal e, assim, puderem imprimir suas perspectivas e suas abordagens de avaliação e de regulação.

Nesse sentido, se defendemos uma perspectiva de avaliação pautada nos princípios democráticos/emancipatórios, como fazer para resgatá-los diante de um cenário tão favorável aos índices estabelecidos nos últimos anos? Os índices, além de promoverem a reconfiguração da atual política de avaliação, por induzir a visualização ascendente dos diagnósticos das avaliações externas, materializados em distintas modalidades de avaliação - avaliação do desempenho estudantil (ENADE), avaliação de curso (ACG) e avaliação institucional externa (em detrimento da avaliação interna), também retoma a agenda da política de avaliação do ENC, quando destaca a agenda do desempenho e da expansão, agora no ambiente da regulação estatal-mercantil.

Os índices alteraram a lógica de articulação entre o papel formativo e somativo da avaliação em favor deste último, não apenas pelo seu pressuposto básico de regular a operacionalização das visitas in loco, mas, sobretudo, pela maneira como os sujeitos (avaliadores e avaliados) têm se apropriado e conferido sentido aos diagnósticos das avaliações para 
fundamentar a regulação do sistema de Educação Superior, com destaque para a regulação estatal e do mercado.

Dessa maneira, as forças, os grupos e os projetos de avaliação da Educação Superior, defensores de uma avaliação contextual-participativa, baseada na agenda avaliação articulada à qualidade e à gestão, distinta da anterior, foram derrotados na luta travada no contexto de redefinição do SINAES. As evidências ressaltadas na análise das políticas de avaliação da Educação Superior, ao longo deste trabalho, apontam que a retomada da avaliação baseada em princípios participativos/emancipatórios nesse cenário adverso tende a acontecer por meio dos embates políticos, quando e se os grupos e as forças forem reposicionados no campo da avaliação da Educação Superior nos próximos anos.

\section{Referências}

BARREYRO, G. B. De exames, rankings e mídia. Avaliação, Sorocaba, v. 13, n. 3, p. 863-868, nov. 2008. DOI: 10.1590/S1414-40772008000300017

BARREYRO, G. B.; ROTHEN, J. C. "SINAES" contraditórios: considerações sobre a elaboração do sistema nacional de avaliação da educação superior. Educação \& Sociedade, Campinas, v. 27, n. 96. Especial. p. 955-977, out. 2006. DOI: 10.1590/s010173302006000300015

BARREYRO, G. B.; ROTHEN, J. C. Para uma história da avaliação da educação superior brasileira: análise dos documentos do PARU, CNRES, GERES e PAIUB. Avaliação, Sorocaba, v. 13, n. 1, p. 131-152, mar. 2008. DOI: 10.1590/s1414-40772008000100008

BARREYRO, G. B.; ROTHEN, J. C. O NUPES e a avaliação da educação superior. concepções, propostas e posicionamentos públicos. In: REUNIÃO ANUAL DA ANPED, 33., 2010, Caxambu. Anais eletrônicos... Caxambu: Centro de Convenções, 2010. Disponível em <http://33reuniao.anped.org.br/internas/ver/trabalhos-gt11>. Acesso em: 1 mar. 2017.

BOURDIEU, P. O poder simbólico. Lisboa: Difel, 1989.

BOURDieU, P.; CLAMBOREDON, J. C.; PASSERON, J. C. A profissão de sociólogo: preliminares epistemológicos. 2. ed. Petrópolis: Vozes, 1999.

BRASIL. Lei No 10.861, de 14 de abril de 2004. Institui o Sistema Nacional de Avaliação da Educação Superior - SINAES e dá outras providências. Diário Oficial [da] República Federativa do Brasil, Poder Legislativo, Brasília, DF, 15 abr. 2004. Seção 1, no 72, p. 3-4.

BRASIL. Lei $\mathrm{N}^{\circ}$ 9.131, de 24 de novembro de 1995. Altera dispositivos da Lei $\mathrm{n}^{\circ}$ 4.024, de 20 de dezembro de 1961, e dá outras providências. Diário Oficial [da] República Federativa do Brasil, Poder Legislativo, Brasília, DF, 25 nov. 1995. Edição extra, seção 1, nº 225-A, p. 19257 19258.

BRASIL. Ministério da Educação. Edital No 8, de 4 de abril de 2016. Chamada pública para seleção e credenciamento de elaboradores e revisores. 2016. Disponível em: <http://portal.inep.gov.br/documentos-e-legislacao15>. Acesso em: 10 nov. 2016. 
BRASIL. Ministério da Educação. Portaria Normativa $\mathbf{N}^{\mathbf{o}}$ 4, de 5 de agosto de 2008. Regulamenta a aplicação do conceito preliminar de cursos superiores, para fins dos processos de renovação de reconhecimento respectivos, no âmbito do ciclo avaliativo do SINAES instaurado pela Portaria Normativa $\mathrm{n}^{\mathrm{o}}$ 1, de 2007. Brasília, 2008a. Disponível em: <http://portal.inep.gov.br/documentos-e-legislacao17>. Acesso em: 11 fev. 2017.

BRASIL. Ministério da Educação. Portaria Normativa $\mathbf{N}^{\mathbf{0}}$ 12, de 5 de setembro de 2008. Institui o Índice Geral de Cursos da Instituição de Educação Superior (IGC). Brasília, 2008b. Disponível em: <http://portal.inep.gov.br/documentos-e-legislacao17>. Acesso em: $11 \mathrm{fev}$. 2017.

BRASIL. Ministério de Educação. PAUIB - Programa de Avaliação Institucional das Universidades Brasileiras. Brasília: MEC/SESu, 1994.

BRASIL. Ministério de Educação. Edital No 01 - Programa de Avaliação Institucional das Universidades Brasileiras. Brasília: MEC/SESu, 1993a.

BRASIL. Sistema Nacional de Avaliação da Educação Superior (SINAES). Bases para uma nova proposta de Avaliação da Educação Superior Brasileira. Comissão Especial de Avaliação (CEA). Brasília: MEC, 2003.

BRASIL. Secretaria de Educação Superior. Comissão Nacional de Avaliação. Documento Básico: Avaliação das Universidades Brasileiras. Uma Proposta Nacional. Brasília: SESu, 1993b.

CASTRO, M. H. G. Sistemas de avaliação da educação no Brasil: avanços e desafios. São Paulo

Perspectiva, São Paulo, v. 23, n. 1, p. 5-18, jan./jun. 2009.

CATANI, A. M.; OLIVEIRA, J. F.; DOURADO, L. F. As políticas de gestão e de avaliação acadêmica no contexto da reforma da educação superior. In: MANCEBO, D.; FÁVERO, M. L. A. (Orgs.). Universidade: políticas, avaliação e trabalho docente. São Paulo: Cortez, 2004. p. $251-262$.

CHAUÍ, M. A Universidade em Ruínas. In: TRINDADE, H. (Org.). Universidade em Ruínas: na república dos professores. Petrópolis: Vozes, 1999. p. 211-222.

CUNHA, L. A. Desenvolvimento desigual e combinado no Ensino Superior: Estado e mercado. Educação \& Sociedade, Campinas, v. 25, n. 88, p. 795-817, 2004. DOI: 10.1590/s010173302004000300008

CUNHA, L. A. Ensino superior e universidade no Brasil. In: LOPES, E. M. T.; FARIA FILHO, L. M.; VEIGA, C. G. (Orgs.). 500 anos de educação no Brasil. 2. ed. Belo Horizonte: Autêntica, 2000. p. 606.

DIAS SOBRINHO, J. A avaliação institucional na Universidade Estadual de Campinas: considerações teóricas e processo. Revista Educación Superior y Sociedad, Cresalc/Unesco, Caracas, v. 5, n. 1-2, 1994a. 
DIAS SOBRINHO, J. Avaliação e transformações da educação superior brasileira (1995-2009): do PROVÃO ao SINAES. Avaliação, Sorocaba, v. 15, n. 1, p. 195-224, mar. 2010. DOI: 10.1590/s1414-40772010000100011

DIAS SOBRINHO, J. Avaliação ética e política em função da educação como direito público ou como mercadoria? Educação \& Sociedade, Campinas, v. 25, n. 88, p. 703-725, out. 2004. Disponível em: <http://www.cedes.unicamp.br.html>. Acesso em: 22 ago. 2007. DOI: 10.1590/s0101-73302004000300004

DIAS SOBRINHO, J. Avaliação institucional da Unicamp: processo, discussão, resultados. Campinas: EDUNICAMP, 1994b.

DIAS SOBRINHO, J. Avaliação Institucional, instrumento da qualidade educativa: a experiência da UNICAMP. In: DIAS SOBRINHO, J.; BALZAN, N. C. (Orgs.). Avaliação institucional: teoria e experiências. São Paulo: Cortez, 1995b. p. 53-86.

DIAS SOBRINHO, J. Avaliação institucional: a experiência da Unicamp. Condições, princípios, processo. Pró-Posições, Campinas, v. 6, n. 16, p. 41-54, mar. 1995a.

DIAS SOBRINHO, J. Avaliação institucional: integração e ação integradora. Revista Avaliação, Sorocaba, v. 2, n. 2, p. 19-29, 1997.

DIAS SOBRINHO, J. Avaliação institucional: marcos teóricos e políticos. Revista Avaliação, Sorocaba, v. 1, n. 1, p. 15-24, jul. 1996.

DIAS SOBRINHO, J. Concepções de Universidade e de avaliação institucional. Avaliação, Sorocaba, v. 4, n. 2, p. 29-40, 1999.

DIAS SOBRINHO, J. Editorial. Avaliação, Campinas; Sorocaba, v. 13, n. 3, p. 623-624, nov. 2008a.

DIAS SOBRINHO, J. Qualidade, avaliação: do SINAES a índices. Avaliação, Sorocaba, v. 13, n. 3, p. 833-840, nov. 2008b. DOI: 10.1590/s1414-40772008000300011

DIAS SOBRINHO, J.; BALZAN, N. C. (Orgs.). Avaliação institucional: teoria e experiências. São Paulo: Cortez, 1995.

DURHAM, E. R. A institucionalização da avaliação. Documento de Trabalho 8, Núcleo de Pesquisas sobre Ensino Superior, Universidade de São Paulo, 1990.

DURHAM, E. R. O ensino superior no Brasil: público e privado. Documento de Trabalho 3, Núcleo de Pesquisas sobre Ensino Superior, Universidade de São Paulo, 2003.

DURHAM, E. R. Subsídios para discussão da avaliação do ensino superior. Infocapes, Brasília, v. 4, n. 4, $1996 \mathrm{~b}$.

DURHAM, E. R. Subsídios para discussão de uma nova política para o ensino superior brasileiro. Infocapes, Brasília, v. 4, n. 4, 1996 a. 
DURHAM, E. R.; SCHWARTZMAN, S. Situação e perspectivas do Ensino Superior no Brasil: os resultados de um seminário. Educação Brasileira, Brasília, v. 12, n. 25, p. 181-192, 1990.

GOLDEMBERG, J. O impacto da avaliação na universidade. Documento de Trabalho 2, Núcleo de Pesquisas sobre Ensino Superior, Universidade de São Paulo, 1990.

GOMES, A. M. Exame nacional de cursos e política de regulação estatal do ensino superior. Cadernos de Pesquisa, São Paulo, n. 120, p. 129-149, nov. 2003. DOI: 10.1590/s010015742003000300007

GOMES, A. M. Política de avaliação da educação superior: controle e massificação. Educação \& Sociedade, Campinas, v. 23, n. 80, p. 275-298, set. 2002. DOI: 10.1590/s010173302002008000014

GOMES, A. M.; AZEVEDO, J. M. L. Notas teóricas sobre regulação e educação superior. In: DOURADO, L. F. Políticas e gestão da educação no Brasil: novos marcos regulatórios? São Paulo: Xamã, 2009. p. 183-191.

GOMES, A. M.; OLIVEIRA, J. F. Educação superior como sujeito-objeto de estudo. In: GOMES, A. M.; OLIVEIRA, J. F. (Orgs.). Reconfiguração do campo da educação superior. Campinas: Mercado de Letras, 2012. p. 13-70.

GOMES, A. M.; ROBERTSON, S. L.; DALE, R. The social condition of higher education: globalisation and (beyond) regionalisation in Latin America. Globalisation, societies and education, v. 10, n. 2, p. 221-245, 2012. DOI: 10.1080/14767724.2012.677708

GOMES, A. M.; SILVA, A. L. da. Políticas de avaliação da educação superior no Brasil: um balanço. In: GOMES, A. M.; OLIVEIRA, J. F. (Orgs.) Reconfiguração do campo da educação superior. Campinas: Mercado de Letras, 2012. p. 145-186.

GRELLO, F. B. NUPES: protagonista da Política para Educação Superior Brasileira. 2008. 158 f. Dissertação (Mestrado em Educação) - Universidade Federal de São Carlos, São Carlos, 2008.

HEY, A. P. Bourdieu epistêmico-prático: o espaço de produção acadêmica em Educação Superior no Brasil. Educação \& Linguagem, v. 10, n. 16, p. 86-105, jul./dez. 2007. DOI: 10.15603/2176-1043/el.v10n16p86-105

HEY, A. P. Esboço de uma sociologia do campo acadêmico: a educação superior no Brasil. São Carlos: UFSCAR, FAPESP, 2008.

HOUSE, E. R. Evaluación, ética y poder. Madri: Morata, 1994.

HOUSE, E. R. Evaluación, ética y poder. reimp. Madri: Morata, 2000.

INEP. Nota Técnica INEP/DAES/CONAES $\mathbf{N}^{\mathbf{0}}$ 62, de 9 de outubro de 2014a. Assunto: Definição da estrutura do Relato Institucional. Disponível em: <http://www.anaceu.org.br/wpcontent/uploads/2014/11/Nota-Técnica-no-62-2014-Relato-Institucional.pdf>. Acesso em: 20 nov. 2016. 
INEP. Nota Técnica INEP/DAES/CONAES N ${ }^{\mathbf{0}}$ 65, de 9 de outubro de 2014b. Assunto: Roteiro para Relatório de Autoavaliação Institucional. Brasília, 2014a. Disponível em <http://download.inep.gov.br/educacao_superior/avaliacao_institucional/nota_tecnica/2014/n ota_tecnica_n65_roteiro_relatorio_de_autoavaliacao_institucional.pdf $>$. Acesso em: 20 nov. 2016.

LAHIRE, B. Reprodução ou prolongamentos críticos? Educação \& Sociedade, Campinas, v. 23, n. 78, p. 37-55, abr. 2002. DOI: 10.1590/s0101-73302002000200004

LEITE, D. Ameaças pós-rankings sobrevivência das CPA e da auto-avaliação. Avaliação, Sorocaba, v. 13, n. 3, p. 833-840, nov. 2008. DOI: 10.1590/s1414-40772008000300013

MARTINS, C. B. Notas sobre o Sistema de Ensino Superior Brasileiro Contemporâneo. Revista USP, São Paulo, n. 39, p. 58-82, set./nov. 1998.

MARTINS, C. B. O Ensino Superior Brasileiro nos Anos 90. São Paulo em Perspectiva, São Paulo, v. 14, n. 1, p. 41-60, 2000.

MARTINS, G. M. Credencialismo, corporativismo e avaliação da universidade. Documento de Trabalho 6, Núcleo de Pesquisas sobre Ensino Superior, Universidade de São Paulo, 1990.

MATTOS, P. L. Avaliação e alocação de recursos no ensino superior federal. Documento de Trabalho 7, Núcleo de Pesquisas sobre Ensino Superior, Universidade de São Paulo, 1990.

MENEGHEL, S. Qualidade da educação superior nos dez anos do Sinaes. III Fórum das CPAs de Pernambuco, Juazeiro, 5 de novembro de 2014.

NEIVA, C. C. As Iniciativas de planejamento e avaliação na formulação de políticas públicas para o Ensino Superior. Documento de Trabalho 4, Núcleo de Pesquisas sobre Ensino Superior, Universidade de São Paulo, 1990.

PALHARINI, F. A. Caderno NUPES: o novo protagonista na formulação teórica da política para o ensino superior. In: MOROSINI, M.; SGUISSARDI, V. A educação superior em periódicos nacionais. Espírito Santo: FCAA/CNPq, 1998. p. 189-210.

PAUL, J-J.; RIBEIRO, Z.; PILLATI, O. As iniciativas e as experiências de avaliação do Ensino Superior: Balanço Crítico. Documento de Trabalho 5, Núcleo de Pesquisas sobre Ensino Superior, Universidade de São Paulo, 1990.

PEIXOTO, M. C. L. O debate sobre avaliação da educação superior: regulação ou democratização? In: MANCEBO, D.; FÁVERO, M. L. A. (Org.). Universidade: políticas, avaliação e trabalho docente. São Paulo: Cortez, 2004. p. 171-188.

POLIDORI, M. M. Políticas de avaliação da educação superior brasileira: PROVÃO, SINAES, IDD, CPC, e... outros índices. Avaliação, Sorocaba, v. 14, n. 2, p. 439-452, jul. 2009. DOI: 10.1590/s1414-40772009000200009

RISTOFF, D. Avaliação Institucional e a Mídia. Avaliação, Sorocaba, v. 2, n. 1, p. 61-64, 1997b. 
RISTOFF, D. Avaliação institucional: pensando princípios. Revista Educación Superior y Sociedad, Caracas, v. 5, n. 1-2, p. 87-98, 1994.

RISTOFF, D. Avaliação na Universidade Federal de Santa Catarina. Avaliação, Sorocaba, v. 1, n. 1, p. 47-53, 1996a.

RISTOFF, D. Avaliar dá certo. Universidade Viva, Florianópolis, v. 1, n. 1, p. 8-9, 1995.

RISTOFF, D. Princípios do Programa de Avaliação Institucional. Avaliação, Sorocaba, v. 1, n. 1, p. 47-53, 1996b.

RISTOFF, D. Privatização não faz escola. Avaliação, Sorocaba, v. 2, n. 4, p. 45-48, 1997 a.

SAUL, A. M. Avaliação emancipatória: desafios à teoria e à prática de avaliação e reformulação de currículo. São Paulo: Cortez, 2001.

SCHWARTZMAN, S. O contexto institucional e político da avaliação do ensino superior. Documento de Trabalho 3, Núcleo de Pesquisas sobre Ensino Superior, Universidade de São Paulo, 1990.

SILVA, A. L. da. Avaliação institucional no Sistema Nacional de Avaliação da Educação Superior (SINAES). 2015. 376 f. Tese (Doutorado em Educação) - Centro de Educação da Universidade Federal de Pernambuco, Recife, 2015.

SILVA, A. L. da; GOMES, A. M. Avaliação institucional no contexto do SINAES: a CPA em questão. Avaliação, Campinas, v. 16, n. 3, p. 573-601, 2011. DOI: 10.1590/s141440772011000300005

SOUZA, P. R. O Provão: uma ousadia necessária. In: SOUZA, P. R. A revolução gerenciada: educação no Brasil - 1995-2002. São Paulo: Prentice Hall, 2005. p. 147-170.

TRINDADE, H. Avaliação institucional das universidades brasileiras: resistência e construção. Avaliação, Sorocaba, v. 1, n. 1, p. 9-14, 1996.

TRINDADE, H. O novo contexto da avaliação nas universidades federais. Pró-Posições, Campinas, v. 6, n. 1, p. 33-40, mar. 1995.

TRINDADE, H. Projeto de Avaliação da ANDIFES. Revista Educación Superior y Sociedad, Caracas, v. 5, n. 1-2, 1994.

VERHINE, R. E. Avaliação e regulação da educação superior: uma análise a partir dos primeiros 10 anos do SINAES. Avaliação, Sorocaba, v. 20, n. 3, p. 603-619, 2015. DOI: 10.1590/s141440772015000300003

WEBER, S. Avaliação e regulação da educação superior: conquistas e impasses. Educação \& Sociedade, Campinas, v. 31, n. 113, p. 1247-1269, out./dez. 2010. DOI: 10.1590/s010173302010000400011 
ZAINKO, M. A. S. Avaliação da educação superior no Brasil: processo de construção histórica. Avaliação, Sorocaba, v. 13, n. 3, p. 827-831, nov. 2008. DOI: 10.1590/s141440772008000300012

ZANDAVALLI, C. B. Avaliação da educação superior no Brasil: os antecedentes históricos do SINAES. Avaliação, Sorocaba, v. 14, n. 2, p. 385-438, jul. 2009. DOI: 10.1590/s141440772009000200008

Recebido em 14/04/2017

Versão corrigida recebida em 27/07/2017

Aceito em 01/08/2017

Publicação online em 09/08/2017 